\title{
NEUTRONIC ANALYSIS OF THE CANDIDATE MULTI-LAYER CLADDING MATERIALS WITH ENHANCED ACCIDENT TOLERANCE FOR WWER REACTORS
}

\author{
OndřEJ NovÁK ${ }^{a, *}, \quad$ MARTIN ŠEveČEK ${ }^{a, b}$ \\ ${ }^{a}$ Department of Nuclear Reactors, Faculty of Nuclear Sciences and Physical Engineering, Czech Technical \\ University in Prague, Prague, Czech Republic, V Holešovičkách 2, Prague 8, Czech Republic \\ ${ }^{b}$ Department of Nuclear Science and Eng., Massachusetts Institute of Technology, Cambridge, USA \\ * corresponding author: ondrej.novak2@fjfi.cvut.cz
}

\begin{abstract}
The paper summarizes preliminary results of neutronic analysis of candidate ATF cladding materials that are under development at the CTU in Prague. To evaluate basic neutronics-related characteristics the Serpent code was used which is a Monte-Carlo based simulation tool. A model of WWER fuel was developed and basic neutronic analysis performed. All coating materials entail certain reactivity penalty compared to reference uncoated cladding that was quantified. The coating of cladding affects also other neutron-physical parameters of cores that modify the performance of the WWER reactors that are discussed.
\end{abstract}

KEYWORDS: WWER, nuclear fuel, cladding, accident tolerant fuel, neutronics, serpent.

\section{INTRODUCTION}

New types of nuclear fuels for Light Water Reactors with enhanced accident tolerance have been recently researched around the world. The concepts considered as future Accident Tolerant Fuels (ATF) include a development of completely new fuel pellets (nitrides, silicides, FCM) 1], cladding materials (FeCrAl, SiC, Mo-alloys), non-fuel components or slight modifications of current fuel system [2 6]. The modification of current fuel system is considered as a near-term concept which can be developed and adopted by the industry in less than 10 years [7. Most of the ATF concepts entails a certain reactivity penalty that has to be precisely determined during the development due to economical and operational concerns.

Many of the recent papers and reports focused on neutronic performance of ATF fuel concepts for traditional PWR and BWR reactors [8-11]. However, the ATF fuels can and should be employed also in the WWER reactors that are in operation in the Czech Republic, Bulgaria, Slovakia, Hungary, Finland, Ukraine, India, and Russia. The WWER reactors perform similarly to PWR reactors in the accidental and transient conditions and therefore most of the material and thermal testing performed in PWR conditions is valid also for WWER reactors [12. However, the WWER reactors have their unique specifics including hexagonal fuel assembly geometry, fuel assembly shroud, different coolant chemistry, different materials or harder neutron spectrum. These specific aspects affect in particular neutron-physical performance of the fuel.

For that reason, models of neutronics performance of the reactor WWER-1000 were developed in the Serpent code, which is a well-known Monte-Carlo

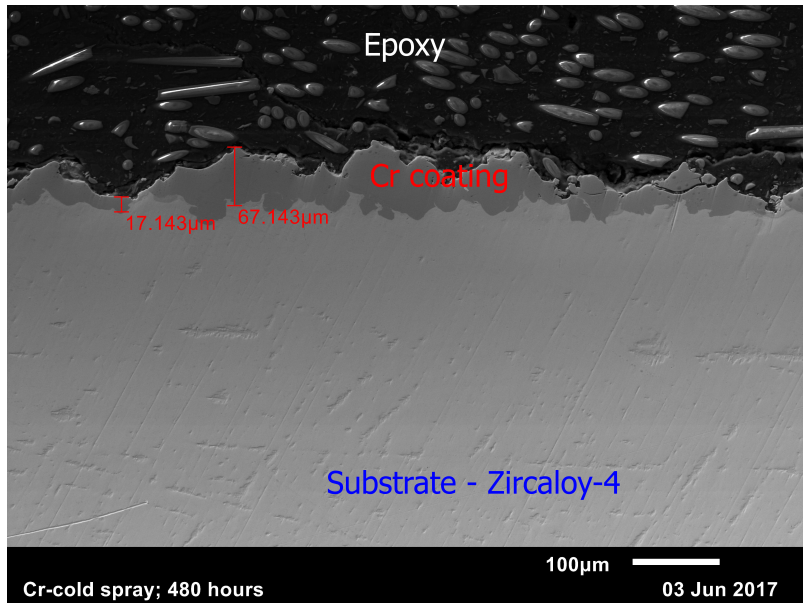

FiguRE 1. SEM micrograph of Cr cold-spray coated Zircaloy-4 cladding with nonuniform coating thickness. The top surface can be finished by polishing but the interface will remain nonhomogeneous due to high hardness of $\mathrm{Cr}$ particles.

based code, developed in the VTT, Finland [13]. This model was used to analyze the performance of different multi-component claddings considered as potential candidates for the ATF development. Some of the concepts have been developed at the CTU [14] or MIT [15] and some are considered as alternative options and will be investigated in future research. All studied concepts are based on the Zircaloy-4 alloy substrate (isotopic material composition is noted in Table 2). This alloy serves as a substrate on which different coating materials are applied. The coating materials include Chromium nitride, Chromium, Zirconium silicate, $\mathrm{FeCrAl}$ or Molybdenum. An example of Zircaloy-4 cladding coated by pure chromium using 


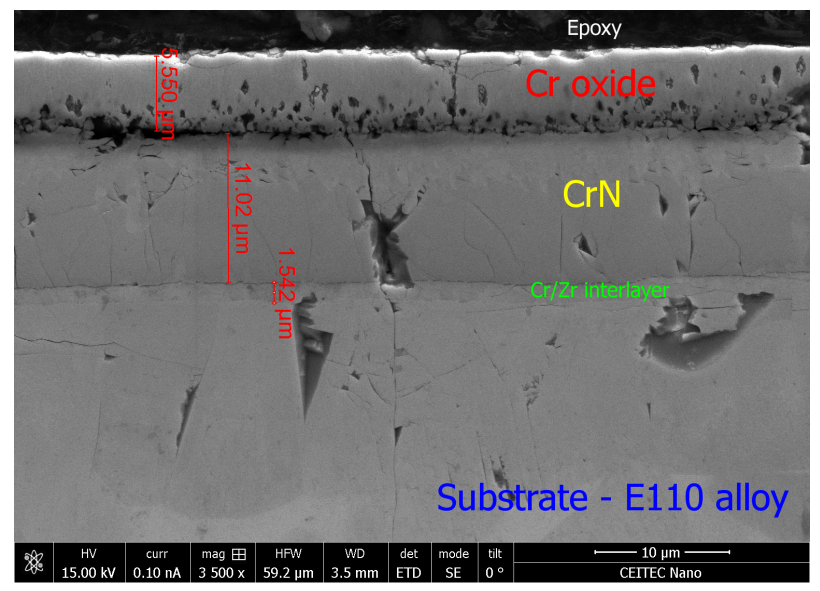

FIGURE 2. SEM micrograph of E110 cladding coated using PVD with CrN after high temperature steam oxidation at $1200^{\circ} \mathrm{C}$ for 9 minutes. Even after oxidation the coating is homogeneous and its thickness can be easily controlled.

cold spray process is shown in Figure 1, other concept is a cladding coated by Physical Vapor Deposition (PVD) method with CrN. This coating is under testing at CTU in Prague and an example of CrN coated cladding exposed to $1200^{\circ} \mathrm{C}$ steam fro 9 minutes is shown in Figure 2. As can be seen from both figure, different deposition technique produce coatings with different characteristics. Cold-spray coatings are more non-uniform and thicker. PVD coatings are generally thinner because the deposition is very slow. PVD can however produce very homogenous high-quality coatings, parameters of which can be easily controlled.

Reactivity penalties and the effect of different coatings on cycle length has been studied and detailed studies are still on going. Changes of neutron spectra caused by deposited cladding coatings compared to reference uncoated case are also investigated as well as effects of coatings on change of reactivity coefficients. Different thicknesses of coating materials are studied and simple economic penalties for each material presented. By changing the neutron spectrum in the core, the relative fission power distribution or $\mathrm{Pu}-239$ and other actinides production might change for a particular concept that has been also included in the study. All calculations and their results are directly compared to the uncoated reference Zircaloy-4 cladding alloy that has been by the industry for decades to clearly show potential benefits and negatives of the particular concept.

\section{MOdel AND METHOdOLOGY}

In order to obtain requested neutronics performance parameters, single 2D fuel pin model was developed using the Serpent code (version 2.1.26). WWER fuel pin model is based on real WWER-1000 fuel geometry. Model of the fuel pin is shown in Figure 2. The boundary conditions were set to reflective. Fuel pin parameters and materials used are noted in Table 1 The

\begin{tabular}{cc}
\hline Parameter & Value \\
\hline Outer cladding radius $[\mathrm{mm}]$ & 4.572 \\
Inner cladding radius [mm] & 4.0005 \\
Cladding thickness [mm] & 0.5715 \\
Cladding material & Zircaloy-4 \\
Fuel pellet outer radius [mm] & 3.922 \\
Pin pitch [mm] & 12.75 \\
$\mathrm{UO}_{2}$ density [g/cm $\left.{ }^{3}\right]$ & 10.412 \\
$\mathrm{UO}_{2}$ enrichment $[\mathrm{wt} . \%]$ & 3.8 \\
Zry-4 density $\left[\mathrm{g} / \mathrm{cm}^{3}\right]$ & 8.00 \\
\hline
\end{tabular}

TABLE 1. WWER-1000 fuel pin parameters used in the simulation.

\begin{tabular}{cc}
\hline Isotope & Weight fraction [-] \\
\hline${ }^{90} \mathrm{Zr}$ & 0.49717 \\
${ }^{91} \mathrm{Zr}$ & 0.10963 \\
${ }^{92} \mathrm{Zr}$ & 0.16941 \\
${ }^{94} \mathrm{Zr}$ & 0.17542 \\
${ }^{96} \mathrm{Zr}$ & 0.028864 \\
${ }^{120} \mathrm{Sn}$ & 0.015 \\
${ }^{56} \mathrm{Fe}$ & 0.002 \\
\hline
\end{tabular}

TABLE 2. Zircaloy-4 isotopic composition.

fuel enrichment was optimized for better performance of the Monte Carlo calculation. Both transport and burnup calculations were used for studied materials.

To obtain accurate results also for high burnup value, high number of burn steps ${ }^{1}$ and high number of neutron particles were simulated in many cycles ${ }^{2}$ Moreover, fuel pellet and cladding were divided into 5 radial regions that were burned separately to enhance depletion accuracy. B1 fundamental mode calculation was applied as well. The newest ENDF/B-VII.1 library was used as a source of all nuclear data. Power density $0.03554 \mathrm{~kW} / \mathrm{g}$ was used for all calculations. Main calculation parameters (temperature, boric acid concentration) simulated representative conditions of the WWER-1000 reactor core. These calculation parameters are summarized in Table 1 Boric acid concentration is based on the middle cycle value, temperatures refer to average material temperature under nominal conditions (at the full reactor power).

\section{StUdiEd MATERIALS}

Several promising coating materials were tested in this neutron analysis study. The choice of coating materials is based on evaluation metrics for accident tolerant fuel concepts developed specifically for the WWER reactors [16. Considered materials include namely: $\mathrm{CrN}, \mathrm{Cr}_{2} \mathrm{~N}, \mathrm{Cr}, \mathrm{ZrSi}_{2}, \mathrm{SiC}, \mathrm{Ti}, \mathrm{FeCr}_{10} \mathrm{Al}_{6}$,

\footnotetext{
${ }^{1}$ Following burnup steps were used: $0.0001,0.09,0.26,0.5$, $1,1.5,2,2.5,3,3.5,4,4.5,5,6,7,8,9,10,11,12,14,16,18$, $20,22,24,26,28,30,32,34,36,38,40,42,44,47,50,53,56$, $60,63,70$

2400000 neutrons per cycle, 400 active cycles and 50 inactive cycles
} 


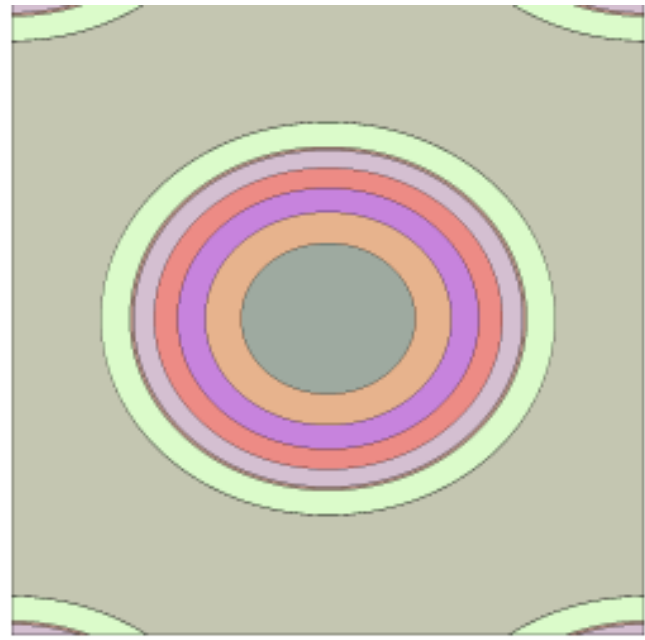

Figure 3. Fuel pin model from the Serpent code. The cladding and pellet are divided into several concentric rings to allow high precision of the simulation of isotopic changes.

Mo. Other concepts that are under development elsewhere 17] are also considered, however results are not presented here: TiN, TiAlN, AlCrN, $\mathrm{Ti}_{2} \mathrm{AlC}$, $\mathrm{Ti}-\mathrm{Si}-\mathrm{C}, \mathrm{Zr}-\mathrm{Al}-\mathrm{C}$. Most promising concepts (that are currently under development at CTU in Prague) were calculated with different coating thicknesses and with full burnup calculations. Calculation regime for each material is noted in Table 5. This selection resulted from very high computational requirements, especially the burnup calculation is extremely time consuming. All considered coating thicknesses used are noted in Table 4

The thicknesses of coatings considered are based on experience with high-temperature testing of respective concepts. The protective nature of coatings with thickness of 5 microns and lower is very limited [14]. Moreover, some deposition techniques, namely cold-spray process, produce non-uniform coatings and it is therefore necessary to consider higher thicknesses in order to ensure uniform layer of coating. An example of cold spray-coated sample is shown in Figure 1. The maximal thickness is based on potential coating stability and also economic consequences. It should be noted, that the optimal thickness of the coating is between 15-60 microns from the perspective of hightemperature testing. Because each coating entails certain reactivity penalty its thickness should be reduced. The thickness of the final concept will be based on compromise between oxidation resistance and economical limitations.

The coating layer generally negatively impacts multiplication factor resulting in shortening of fuel cycle which has negative economic consequences on whole power plant. The decrease in effective power days is not easy to predict using only fuel pin calculation, due to the general influences of fuel handling and core design, different fuel pin positions in fuel assemblies and reactor operation history. However, relative impact of

\begin{tabular}{cc}
\hline Parameter & Value \\
\hline Fuel temperature & $1005 \mathrm{~K}$ \\
Soluble boron concentration & $525 \mathrm{ppm}(3 \mathrm{~g} / \mathrm{kg})$ \\
Coolant density & $0.7169 \mathrm{~g} / \mathrm{cm}^{3}$ \\
Number of radial pin regions & 5 \\
Coolant temperature & $578 \mathrm{~K}$ \\
\hline
\end{tabular}

TABLE 3. Stationary parameters of the Serpent calculation chosen based on standard WWER-1000 operational characteristics.

coatings on fuel cycle length can be estimated.

The methodology used is based on the multiplication factor for final burnup value $\left(70 \mathrm{MWd} / \mathrm{kg}_{U}\right)$ in case of fuel pin without coating. Then from the results for fuel pin with coating, burnup point with similar multiplication factor is estimated. Difference between estimated value and the final burnup value is calculated and is used as factor describing the decrease in fuel cycle length. The breakpoint value depends mostly on fuel costs (especially additional enrichment costs). Final decision of economical acceptance should be based on deeper economical study and will be presented in future.

\section{Results}

As was previously mentioned, several coating materials were simulated ( $\mathrm{CrN}, \mathrm{Cr}, \mathrm{ZrSi}_{2}, \mathrm{SiC}, \mathrm{Ti}, \ldots$ ) Most of these materials underwent precise burnup calculation. Comparison of all calculated cases for zero burnup is noted in the Table 6. The column Difference shows difference in reactivity in $\mathrm{pcm}$ between the reference case without coating material and coated concept. As it is shown in the table, decrease in multiplication factor was observed for all materials and the absolute value of the decrease is closely linked to the higher absorption cross section of coating materials.

Decrease in multiplication factor results in shorter fuel cycle which has direct impact on power plant profit. The $1 \%$ decrease in fuel cycle length can be considered as acceptable when consequently increasing safety of the power plant. Moreover, $1 \%$ decrease in fuel cycle length offers sufficient thickness of coating material so that coating material can provide requested safety enhancement. Some materials resulted in only small decrease in $\mathrm{k}_{\text {eff }}$, which means that impact on fuel cycle length is not crucial. However, Molybdenum coating has significant impact on fuel cycle length. All materials, except Mo, has decrease in fuel cycle length around $1 \%$ for $20 \mu \mathrm{m}$ thick coating. For $50 \mu \mathrm{m}$ thick coating is the decrease above $2 \%$. Molybdenum reaches $4 \%$ for $50 \mu \mathrm{m}$. The best material with the lowest fuel cycle length influence can be considered $\mathrm{ZrSi}_{2}$. This coating material even increased multiplication factor for high burnup values when compared to reference case (see the Figure 5).

The data summarized in Table 6 are shown also in Figure 3 The decrease in reactivity corresponds 


\begin{tabular}{cc}
\hline Outer Cladding Radius $[\mathrm{mm}]$ & Coating \\
\hline 4.572 & 0 \\
4.578 & 6 \\
4.581 & 9 \\
4.587 & 15 \\
4.592 & 20 \\
4.602 & 30 \\
4.622 & 50 \\
4.672 & 100 \\
\hline
\end{tabular}

TABLE 4. Coating thicknesses used in calculations and corresponding outer cladding radius. The inner cladding radius is constant.

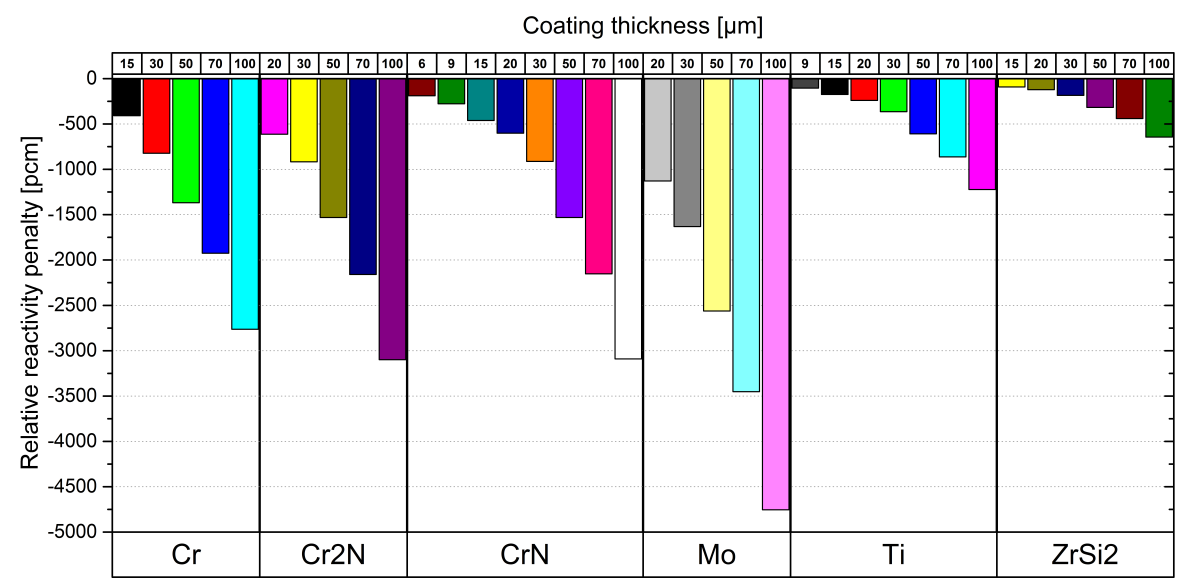

FIGURE 4. Relative reactivity penalty for considered coated claddings with various thicknesses

\begin{tabular}{ccc}
\hline Material & Burnup & Coating thicknesses \\
\hline $\mathrm{CrN}$ & yes & $6,9,15,20,30,50,70,100$ \\
$\mathrm{Cr}$ & yes & $15,30,50,70,100$ \\
$\mathrm{SiC}$ & yes & $15,20,100$ \\
$\mathrm{Ti}$ & no & $9,15,20,30,50,70,100$ \\
$\mathrm{ZrSi}_{2}$ & yes & $15,20,30,50,70,100$ \\
$\mathrm{Cr}_{2} \mathrm{~N}$ & no & $20,30,50,70,100$ \\
$\mathrm{Mo}$ & no & $20,30,50,70,100$ \\
\hline
\end{tabular}

TABLE 5. Coating material and tested parameters.

clearly to absorption neutron cross section. The penalty of coatings also increases with thickness of coatings as expected.

The changes in neutron flux for considered materials are shown in Figure 6. Decrease in the thermal part of neutron spectrum was observed. This change may lead to changes of reactivity coefficients and effective cross sections of materials in the core. This decrease suggest the decrease in reactivity of whole system described above. On the other hand, an increase in neutron flux in epithermal and fast neutron spectrum affect isotopic composition of materials due to different effective absorption. This results need however further confirmation and additional full core calculations. The change of reactivity coefficients suggest that core behavior in reactivity-related events (RIA, MSLB) will differ from the reference case. Ad-

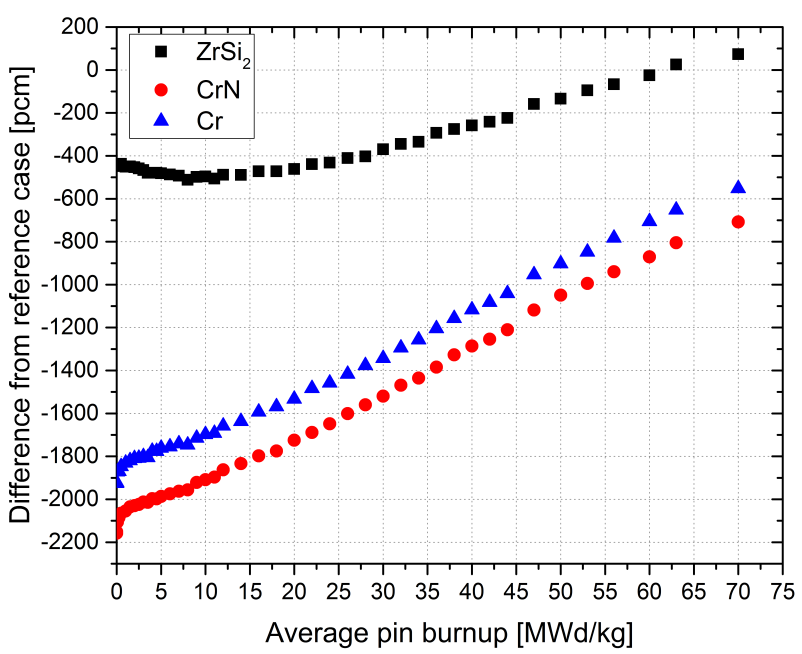

FiguRE 5. Multiplication factor dependency on burnup value for $70 \mu \mathrm{m}$ coating

ditionally, different neutron spectrum in the core will lead to different material composition including minor actinides that are crucial from the point of reactor operation.

Isotopic changes of coating materials were mostly dependent on neutron capture probabilities of involved isotopes in coating. Isotopic composition of pellets differs due to changes in neutron spectrum described above. As an example the production of $\mathrm{Pu}-239$ dur- 


\begin{tabular}{|c|c|c|c|c|c|}
\hline Coating material & $\begin{array}{l}\text { Coating } \\
\text { Thickness } \\
{[\mu \mathrm{m}]}\end{array}$ & $\begin{array}{l}\text { Outer } \\
\text { Cladding } \\
\text { Radius } \\
{[\mathrm{mm}]}\end{array}$ & Keff [-] & Keff uncertainty & $\begin{array}{l}\text { Difference } \\
{[\mathrm{pcm}]}\end{array}$ \\
\hline Reference case & 0 & 4.572 & 1.28949 & $3.60 \mathrm{E}-05$ & 0 \\
\hline $\mathrm{Cr}$ & 15 & 4.587 & 1.28424 & $3.90 \mathrm{E}-05$ & -409 \\
\hline $\mathrm{Cr}$ & 30 & 4.602 & 1.27897 & $3.50 \mathrm{E}-05$ & -823 \\
\hline $\mathrm{Cr}$ & 50 & 4.622 & 1.27209 & $3.70 \mathrm{E}-05$ & -1368 \\
\hline $\mathrm{Cr}$ & 70 & 4.642 & 1.26513 & $4.00 \mathrm{E}-05$ & -1925 \\
\hline $\mathrm{Cr}$ & 100 & 4.672 & 1.25482 & $3.80 \mathrm{E}-05$ & -2763 \\
\hline $\mathrm{Cr}_{2} \mathrm{~N}$ & 20 & 4.592 & 1.28163 & $3.50 \mathrm{E}-05$ & -613 \\
\hline $\mathrm{Cr}_{2} \mathrm{~N}$ & 30 & 4.602 & 1.27777 & $3.70 \mathrm{E}-05$ & -917 \\
\hline $\mathrm{Cr}_{2} \mathrm{~N}$ & 50 & 4.622 & 1.27005 & $3.60 \mathrm{E}-05$ & -1531 \\
\hline $\mathrm{Cr}_{2} \mathrm{~N}$ & 70 & 4.642 & 1.26224 & $4.00 \mathrm{E}-05$ & -2159 \\
\hline $\mathrm{Cr}_{2} \mathrm{~N}$ & 100 & 4.672 & 1.25073 & $4.10 \mathrm{E}-05$ & -3099 \\
\hline $\mathrm{CrN}$ & 6 & 4.578 & 1.28357 & $3.60 \mathrm{E}-05$ & -461 \\
\hline $\mathrm{CrN}$ & 9 & 4.581 & 1.28592 & $3.70 \mathrm{E}-05$ & -278 \\
\hline $\mathrm{CrN}$ & 15 & 4.587 & 1.28707 & $3.70 \mathrm{E}-05$ & -188 \\
\hline $\mathrm{CrN}$ & 20 & 4.592 & 1.28179 & $3.80 \mathrm{E}-05$ & -601 \\
\hline $\mathrm{CrN}$ & 30 & 4.602 & 1.27783 & $3.60 \mathrm{E}-05$ & -912 \\
\hline $\mathrm{CrN}$ & 50 & 4.622 & 1.27005 & $3.80 \mathrm{E}-05$ & -1531 \\
\hline $\mathrm{CrN}$ & 70 & 4.642 & 1.26233 & $3.80 \mathrm{E}-05$ & -2152 \\
\hline $\mathrm{CrN}$ & 100 & 4.672 & 1.25083 & $3.60 \mathrm{E}-05$ & -3091 \\
\hline Mo & 20 & 4.592 & 1.27511 & $3.80 \mathrm{E}-05$ & -1128 \\
\hline Mo & 30 & 4.602 & 1.26880 & $3.60 \mathrm{E}-05$ & -1631 \\
\hline Mo & 50 & 4.622 & 1.25727 & $3.90 \mathrm{E}-05$ & -2563 \\
\hline Mo & 70 & 4.642 & 1.24646 & $4.00 \mathrm{E}-05$ & -3452 \\
\hline Mo & 100 & 4.672 & 1.23096 & $4.10 \mathrm{E}-05$ & -4755 \\
\hline $\mathrm{SiC}$ & 15 & 4.587 & 1.28850 & $3.70 \mathrm{E}-05$ & -77 \\
\hline $\mathrm{SiC}$ & 20 & 4.592 & 1.28817 & $3.80 \mathrm{E}-05$ & -102 \\
\hline $\mathrm{SiC}$ & 100 & 4.672 & 1.28237 & $3.60 \mathrm{E}-05$ & -555 \\
\hline $\mathrm{Ti}$ & 9 & 4.581 & 1.28814 & $3.70 \mathrm{E}-05$ & -105 \\
\hline $\mathrm{Ti}$ & 15 & 4.587 & 1.28725 & $3.70 \mathrm{E}-05$ & -174 \\
\hline $\mathrm{Ti}$ & 20 & 4.592 & 1.28641 & $3.80 \mathrm{E}-05$ & -239 \\
\hline $\mathrm{Ti}$ & 30 & 4.602 & 1.28481 & $3.90 \mathrm{E}-05$ & -364 \\
\hline $\mathrm{Ti}$ & 50 & 4.622 & 1.28170 & $3.70 \mathrm{E}-05$ & -608 \\
\hline $\mathrm{Ti}$ & 70 & 4.642 & 1.27846 & $3.70 \mathrm{E}-05$ & -863 \\
\hline $\mathrm{Ti}$ & 100 & 4.672 & 1.27391 & $3.60 \mathrm{E}-05$ & -1223 \\
\hline $\mathrm{ZrSi}_{2}$ & 15 & 4.587 & 1.28832 & $3.80 \mathrm{E}-05$ & -91 \\
\hline $\mathrm{ZrSi}_{2}$ & 20 & 4.592 & 1.28793 & $3.70 \mathrm{E}-05$ & -121 \\
\hline $\mathrm{ZrSi}_{2}$ & 30 & 4.602 & 1.28711 & $3.60 \mathrm{E}-05$ & -185 \\
\hline $\mathrm{ZrSi}_{2}$ & 50 & 4.622 & 1.28542 & $3.90 \mathrm{E}-05$ & -317 \\
\hline $\mathrm{ZrSi}_{2}$ & 70 & 4.642 & 1.28384 & $4.00 \mathrm{E}-05$ & -440 \\
\hline $\mathrm{ZrSi}_{2}$ & 100 & 4.672 & 1.28123 & $3.90 \mathrm{E}-05$ & -645 \\
\hline
\end{tabular}

TABLE 6. Multiplication factors for different coating materials and thicknesses. 


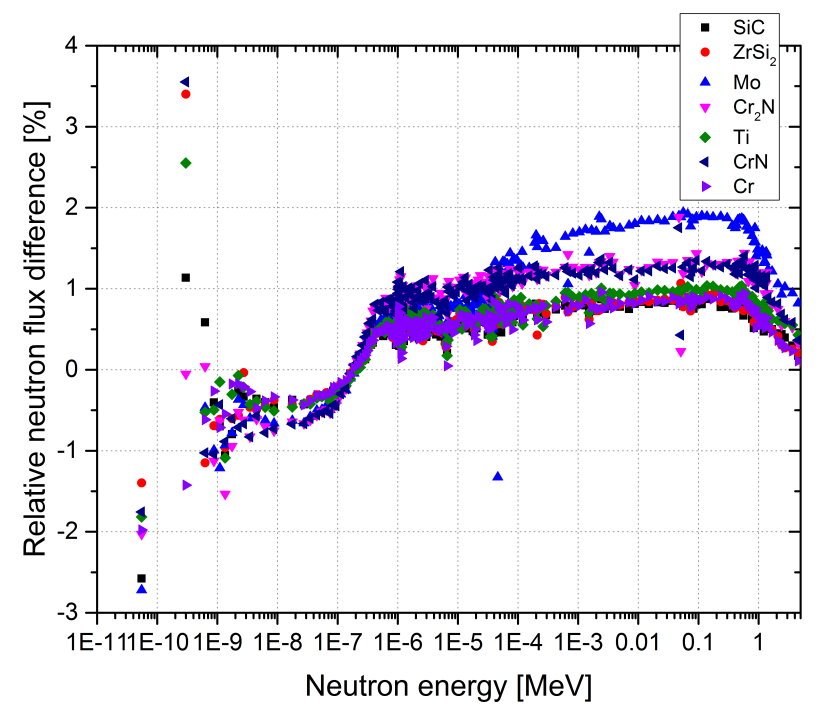

Figure 6. Flux difference between the reference case (cladding without any coating) and claddings with fully dense 15 microns thick coatings.

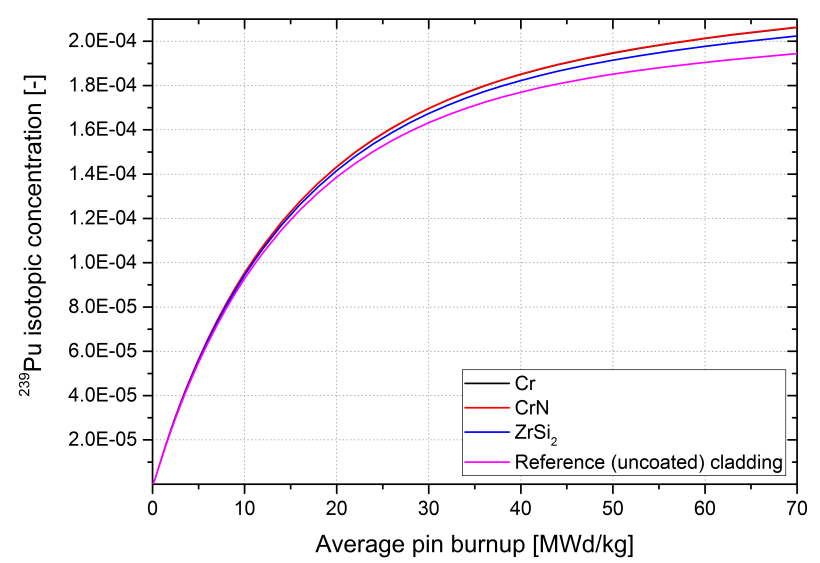

Figure 7. Change in Plutonium-239 concentration for different coating materials

ing burnup is shown in Figure 7 for different cladding materials. The effect increases with increasing burnup as expected. Different breeding ratio and change in reactivity coefficients affect also other reactor performance parameters as axial offset, radial peaking, material irradiation damage or performance during accidents e.g. RIA [10]. For that reason, full core calculations need to be performed before concluding the evaluation of different ATF concepts including the precise definition of effective cross sections.

\section{Conclusion}

Vast selection of coating materials considered for ATF cladding was studied in area of neutronic performance of a WWER reactor. Impact of coating layer to multiplication factor and reactivity during whole fuel cycle was studied. In addition, changes of material itself caused by neutron interaction were calculated and discussed. Moreover, neutron flux changes were studied as well. Multiplication factor in all cases decreased due to higher neutron absorption of coating materials. This causes reducing of cycle length having economic consequences for utilities. For that reason, the thickness of the coatings need to be optimized not only from the perspective of safety enhancement but also from economical perspectives. By using coated claddings, the neutron spectrum in a reactor will change. This brings new questions related to operation of a reactor and its safety. Detailed full-core calculations need to be performed in order to precisely quantify the effects of particular coatings. However, this study reveals only neutronics-related performance of the ATF claddings. To conclude and select the most appropriate coating material enhancing the accident tolerance of WWER reactors, other studies from different field must be included.

\section{ACKNOWLEDGEMENTS}

This work was supported by the Grant Agency of the Czech Technical University in Prague, grant No. SGS16/252/OHK4/3T/14 and IAEA CRP 21065 "Development and Testing of Coated Fuel Cladding for VVER Reactors with Enhanced Accident Tolerance".

\section{REFERENCES}

[1] N. R. Brown, M. Todosow, A. Cuadra. Screening of advanced cladding materials and $\mathrm{UN}-\mathrm{U} 3 \mathrm{Si} 5$ fuel. Journal of Nuclear Materials 462:26-42, 2015. DOI:10.1016/j.jnucmat.2015.03.016

[2] R. B. Rebak, K. A. Terrani, R. M. Fawcett. FeCrAl Alloys for Accident Tolerant Fuel Cladding in Light Water Reactors p. V06BT06A009, 2016. DOI:10.1115/PVP2016-63162.

[3] H.-G. Kim, J.-H. Yang, W.-J. Kim, Y.-H. Koo. Development Status of Accident-tolerant Fuel for Light Water Reactors in Korea. Nuclear Engineering and Technology 48(1):1-15, 2016. DOI:10.1016/j.net.2015.11.011

[4] B. Cheng, Y.-J. Kim, P. Chou. Improving Accident Tolerance of Nuclear Fuel with Coated Mo-alloy Cladding. Nuclear Engineering and Technology 48(1):16-25, 2016. DOI:10.1016/j.net.2015.12.003.

[5] IAEA. Accident Tolerant Fuel Concepts for Light Water Reactors 2016.

[6] S. Bragg-Sitton. Development of advanced accident-tolerant fuels for commercial LWRs. Nuclear News 57(3):83, 2014.

[7] I. Charit. Accident tolerant nuclear fuels and cladding materials. JOM 70(2):173-175, 2018. DOI:10.1007/s11837-017-2701-3.

[8] N. M. George, K. Terrani, J. Powers, et al. Neutronic analysis of candidate accident-tolerant cladding concepts in pressurized water reactors. Annals of Nuclear Energy 75:703-712, 2015. DOI:10.1016/j.anucene.2014.09.005

[9] I. Younker, M. Fratoni. Neutronic evaluation of coating and cladding materials for accident tolerant fuels. Progress in Nuclear Energy 88:10-18, 2016. DOI:10.1016/j.pnucene.2015.11.006 
[10] N. R. Brown, A. J. Wysocki, K. A. Terrani, et al. The potential impact of enhanced accident tolerant cladding materials on reactivity initiated accidents in light water reactors. Annals of Nuclear Energy 99:353-365, 2017. DOI:10.1016/j.anucene.2016.09.033.

[11] G. J. Youinou, R. S. Sen. Impact of AccidentTolerant Fuels and Claddings on the Overall Fuel Cycle: A Preliminary Systems Analysis. Nuclear Technology 188(2):123-138, 2014. DOI:10.13182/NT14-22.

[12] H. Weidinger. PWR and WWER fuel performance. A comparison of major characteristics 2005.

[13] J. Leppänen. Serpent - a continuous-energy Monte Carlo reactor physics burnup calculation code. VTT Technical Research Centre of Finland 4, 2013.
[14] J. Krejci, M. Sevecek, L. Cvrcek. Development of Chromium and Chromium Nitride Coated Cladding for VVER Reactors. 2017 WRFPM .

[15] M. Ševeček, A. Gurgen, A. Seshadri, et al. Development of Cr Cold-Spray Coated Fuel Cladding with Enhanced Accident Tolerance. Nuclear Engineering and Technology DOI:10.1016/j.net.2017.12.011

[16] M. Sevecek, M. Valach. Evaluation Metrics Applied to Accident Tolerant Fuel Cladding Concepts for VVER Reactors. Acta Polytechnica CTU Proceedings 4:89, 2016. DOI:10.14311/AP.2016.4.0089

[17] C. Tang, M. Stueber, H. J. Seifert, M. Steinbrueck. Protective coatings on zirconium-based alloys as accidenttolerant fuel (ATF) claddings. Corrosion Reviews 35(3):141-165, 2017. DOI:10.1515/corrrev-2017-0010 